\title{
Features of Surface Structures of Alumina and Titanium Dioxide Nanoparticles Produced Using Different Synthesis Methods
}

\author{
Vyacheslav Syzrantsev, ${ }^{1,2}$ Evgenii Paukshtis, ${ }^{3}$ Tatyana Larina, ${ }^{3}$ Yuriy Chesalov, ${ }^{3}$ \\ Sergey Bardakhanov $\mathbb{1}^{2},{ }^{2,4,5}$ and Andrey Nomoev ${ }^{1,6}$ \\ ${ }^{1}$ Buryat State University, 24a Smolin Str., Ulan-Ude 670000, Russia \\ ${ }^{2}$ Khristianovich Institute of Theoretical and Applied Mechanics of Siberian Branch of Russian Academy of Science, \\ 4/1 Institutskaya Str., Novosibirsk 630090, Russia \\ ${ }^{3}$ Institute of Catalysis of Siberian Branch of Russian Academy of Science, 7 Lavrentiev Av., Novosibirsk 630090, Russia \\ ${ }^{4}$ Lavrentiev Institute of Hydrodynamics of Siberian Branch of Russian Academy of Science, 15 Lavrentiev Av., \\ Novosibirsk 630090, Russia \\ ${ }^{5}$ Novosibirsk State Technical University, 20 Karl Marks Av., Novosibirsk 630073, Russia \\ ${ }^{6}$ Institute of Physical Material Science of Siberian Branch of Russian Academy of Science, 6 Sahyanova Str., \\ Ulan-Ude 670047, Russia
}

Correspondence should be addressed to Sergey Bardakhanov; bard@itam.nsc.ru

Received 20 September 2017; Revised 5 December 2017; Accepted 10 December 2017; Published 23 January 2018

Academic Editor: Giuseppe Compagnini

Copyright (C) 2018 V. V. Syzrantsev et al. This is an open access article distributed under the Creative Commons Attribution License, which permits unrestricted use, distribution, and reproduction in any medium, provided the original work is properly cited.

\begin{abstract}
A comparative study of the scope and surface properties of alumina $\left(\mathrm{Al}_{2} \mathrm{O}_{3}\right)$ and titanium dioxide $\left(\mathrm{TiO}_{2}\right)$ nanoparticles, synthesized using different methods, was carried out using Fourier-transform infrared spectroscopy (FTIR), ultraviolet UV-Vis diffuse reflection spectroscopy (UV-Vis DRS), and Raman spectroscopy, as well as X-ray diffraction methods. It is shown that the differences in the synthesis methods can change the surface properties of the nanoparticles, while maintaining the phase composition of the material. The nanoparticles of each material are shown to exhibit unexpected properties. In particular, the special luminescence characteristics of $\mathrm{TiO}_{2}$, a photon-energy shift from the rutile region into that region typical for the anatase, and a significant difference in the Lewis center concentration values for the alumina $\gamma$-phase were observed. This variation in the properties indicates the necessity to involve a wider range of analysis techniques and the importance of precisely characterizing the surface properties. To identify those nanoparticle functional properties that determine their interactions with other materials, a comprehensive study of their phase compositions and surface properties must be completed.
\end{abstract}

\section{Introduction}

Nanoparticles are a common class of inorganic materials, and although their fundamental properties have been studied, some of their characteristics are unique, despite their all having the same phase composition. These differences are determined by the synthesis conditions $[1,2]$. The synthesis method and its conditions determine the interactions of atoms and their association when the nanoparticles are forming. Formation peculiarities may occur during nucleation, either during molecular cluster growth or during association of the nanoparticles [3]. Previous studies [1,4] have shown that a change in the method used to synthesize nanosilica particles led to a change in the nanoparticle structures, from close-packed (aerosil) to strip-like (aerogel). Furthermore, increasing their size while keeping the synthesis method as is resulted in the $(-\mathrm{OH})$ surface groups being replaced with $(-\mathrm{OH})_{2}$.

The properties of nanoparticle surfaces, including the contents of the different functional groups and their heterogeneity, are the most important factors for determining the efficiency of their application. If the surface groups coincide, their heterogeneity, that is, the distribution of the reactivity, becomes critical. Although significant data on the 
surface properties of both titanium dioxide and alumina has been accumulated, interpretations of their donor-acceptor properties are sometimes contradictory. The intensity of the -OH-group absorption is proportional to the specific surface area [5], but the ratio of the bridging to terminal -OH groups [6], in terms of nanoparticles, can vary. Changes in the number of Lewis acid sites occur because of the change in the coordination number of aluminum or oxygen [7].

Obviously, the variation in the synthesis methods may play a crucial role in the catalytic activity of alumina nanoparticles and the photocatalytic activity of titanium dioxide. Thus, we carried out a comparative analysis of the surface properties of their nanoparticles, synthesized by various methods, to estimate the possible interaction between the nanoparticles and their environment.

\section{Materials and Methods}

2.1. Materials. In the present study, $\mathrm{Al}_{2} \mathrm{O}_{3}$ and $\mathrm{TiO}_{2}$ nanopowders, described below, were investigated.

(A) An industrial electron-beam accelerator is used to "physically" evaporate raw solid alumina and titanium dioxide [8]. The electron beam has a relativistic energy of $1.4 \mathrm{MeV}$ with a power of up to $70 \mathrm{~kW}$. The high-temperature vapor cools in the air flow to condense as nanoparticles.

(B) Commercial alumina and titanium oxide nanopowders are produced through the high-temperature flame hydrolysis of corresponding chlorides $\mathrm{AlCl}_{3}$ or $\mathrm{TiCl}_{4}$, together with hydrogen and oxygen [9] (Evonik Industries). Nanopowders of alumina AEROXIDE Alu 130 and titanium dioxide AEROXIDE P25 were investigated.

(C) A plasma-chemistry method in which an aqueous solution of aluminum nitrate $\left(\mathrm{Al}\left(\mathrm{NO}_{3}\right)_{3} 9 \mathrm{H}_{2} \mathrm{O}\right)$ is treated by a high-frequency plasma generator [10] (Siberian Chemical Combine).

(D) Commercial high-purity alumina nanopowder is manufactured from aluminum metal and alcohol, producing high-purity aluminum alkoxide, after which hydrated alumina is produced by the hydrolysis of aluminum alkoxide, with consequent calcination [11] (Sumitomo Chemical). The nanopowder AKP-50 was studied.

(E) To produce titanium oxide using method [12] (Nano Chemical Inc.) the modified wet sulfate process was used. This can be characterized briefly as ...TiOSO $4+\mathrm{H}_{2} \mathrm{O} \rightarrow$ $\mathrm{TiO}_{2}$.

It is necessary to emphasize that technologies (A), (B), and $(\mathrm{C})$ are gas-phase methods of nanopowder production.

\subsection{Methods}

2.2.1. Specific Surface Area of Nanopowders, Phase Composition, and Shape of Nanoparticles. The specific surface area (SSA) and average particle size (APS) of the powders were defined by a liquid nitrogen adsorption method (BrunauerEmmett-Teller (BET) analysis, Sorbi-M) using the standard procedure. Nitrogen was used as a gas-adsorbent. The specific surface measurements were carried out in helium/nitrogen mixtures with nitrogen concentrations of $6,9,15$, and $20 \%$.
The phase type and morphology were studied using $\mathrm{X}$ ray diffraction (HZG-4 diffractometer, $\mathrm{Cu}$ - monochromatic irradiation) and transmission electron microscopy (TEM, JEM-100CX).

2.2.2. Fourier-Transform Infrared (FTIR) Spectroscopy. The surface property measurements were carried out using Fourier-transform infrared (FTIR) spectroscopy with adsorbed pyridine. To obtain solid samples, the initial powders were mixed with barium fluoride, which is transparent around $1000 \mathrm{~cm}^{-1}$ and does not distort the spectrum of the $-\mathrm{OH}$ groups when mixed at a ratio of $1: 2$. The mixtures were pressed into thin wafers $\left(20-30 \mathrm{mg} / \mathrm{cm}^{2}\right)$. Before adsorption, the samples were evacuated to $10^{-3}$ torr at $500^{\circ} \mathrm{C}$ for $2 \mathrm{~h}$. Pyridine was adsorbed at a temperature of $150-160^{\circ} \mathrm{C}$ for 15-20 $\mathrm{min}$. The samples were then evacuated for $60 \mathrm{~min}$ to a pressure of less than $10^{-2}$ torr at the same temperature. The spectra were recorded at a resolution of $4 \mathrm{~cm}^{-1}$ in the region of $1000-4000 \mathrm{~cm}^{-1}$ using a Fourier spectrometer (Shimadzu8300 ) to acquire 200 spectra.

The concentrations of the Lewis-type centers were measured from the integrated intensity of the absorption bands at $1440-1460 \mathrm{~cm}^{-1}$, using an integrated absorption coefficient of 3.5 [13]. The strength was estimated from the location of the two bands, namely, the vibration of the pyridine ring at $1440-1460$ and $1590-1630 \mathrm{~cm}^{-1}$.

2.2.3. Raman Spectroscopy. FT-Raman spectra (3700-100 $\mathrm{cm}^{-1}$, 300 scans, resolution of $4 \mathrm{~cm}^{-1}$, and $180^{\circ}$ geometry) were collected using an RFS 100/S spectrometer (Bruker). The excitation of the 1064-nm line was achieved using a Nd-YAG laser (200-mW output).

2.2.4. Ultraviolet-Visible Diffuse Reflectance Spectroscopy (UV$V$ is DRS). The optical properties of the materials were investigated by diffuse reflectance spectroscopy (UV-Vis DRS) using a UV-2501 PC (Shimadzu) spectrophotometer with an ISR-240A diffuse reflectance attachment. The $\mathrm{TiO}_{2}$ powder samples were placed in a quartz cell with an optical path length of $2 \mathrm{~mm}$. Spectra were recorded with respect to a reflection standard, $\mathrm{BaSO}_{4}$, in the range of $190-900 \mathrm{~nm}$ $\left(11,000-54,000 \mathrm{~cm}^{-1}\right)$ in 2-nm steps. The reflectance coefficients were converted to absorption coefficients using the Kubelka-Munk function, $F(R)=(1-R)^{2} / 2 R$, where $R$ is the reflectance coefficient. The wavelength values were converted to wavenumbers, expressed in $\mathrm{cm}^{-1}$.

Using UV-Vis-DRS spectra, at the edge of the fundamental absorption of the material, we calculated the width of the band gap. The dependences, $\alpha^{1 / 2}=f(h \nu)$, where $\alpha=((1-$ $R)^{2}(2 R) * E_{h v}$, were derived. The power " 1.2 " was used due to the $\mathrm{TiO}_{2}$ being an indirect semiconductor. It was allocated in an area in which the experimental points satisfied a linear law. Furthermore, the linear dependence was extrapolated to the $x$-axis, and the intersection point corresponded to the value of the energy band gap of the semiconductor. 
TABLE 1: Specific surface areas and phase information of samples.

\begin{tabular}{|c|c|c|c|c|c|}
\hline Number & Sample number & Material & $S_{\mathrm{sp}}, \mathrm{m}^{2} / \mathrm{g}$ & Phase type & Synthesis method \\
\hline \multicolumn{6}{|c|}{ Alumina } \\
\hline$(1)$ & (1) & $\mathrm{Al}_{2} \mathrm{O}_{3}$ & 40 & $\gamma$ & (A) Electron beam evaporation [8] \\
\hline$(2)$ & (2) & $\mathrm{Al}_{2} \mathrm{O}_{3}$ & 53 & $\gamma$ & (A) Electron beam evaporation [8] \\
\hline (3) & (3) & $\mathrm{Al}_{2} \mathrm{O}_{3}$ & 94 & $\gamma$ & (A) Electron beam evaporation [8] \\
\hline$(4)$ & $(4)$ & $\mathrm{Al}_{2} \mathrm{O}_{3}$ & 124 & $\gamma$ & (B) High-temperature flame hydrolysis [9] \\
\hline$(5)$ & $(5)$ & $\mathrm{Al}_{2} \mathrm{O}_{3}$ & 5 & Equal parts of $\delta$ and $\theta$ & (C) Plasma-chemistry [10] \\
\hline$(6)$ & $(6)$ & $\mathrm{Al}_{2} \mathrm{O}_{3}$ & 8 & $\alpha$ & (D) Hydrolysis of aluminum alkoxide [11] \\
\hline \multicolumn{6}{|c|}{ Titanium dioxide } \\
\hline$(7)$ & (7) & $\mathrm{TiO}_{2}$ & 42 & Anatase $86 \%$ and rutile $14 \%$ & (A) Electron beam evaporation [8] \\
\hline$(8)$ & (8) & $\mathrm{TiO}_{2}$ & 48 & Anatase $89 \%$ and rutile $11 \%$ & (B) High-temperature flame hydrolysis [9] \\
\hline$(9)$ & $(9)$ & $\mathrm{TiO}_{2}$ & 46 & Rutile & (E) Sulfate process [12] \\
\hline
\end{tabular}

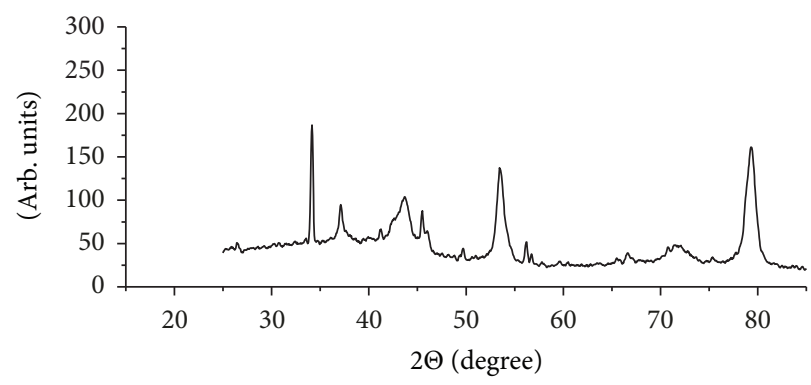

(a)

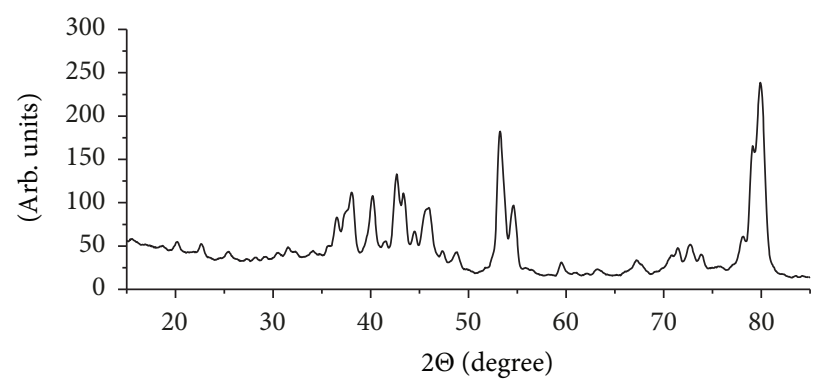

(b)

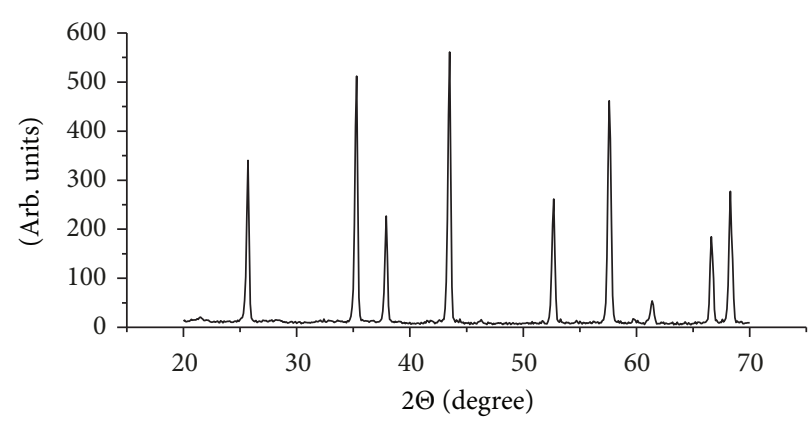

(c)

FIGURE 1: X-ray data for alumina nanoparticles: (a) sample (1), (b) sample (5), and (c) sample (6).

\section{Results}

3.1. Structural Properties and Morphology of Nanopowders. Table 1 lists the specific surface area and phase information. Figure 1 presents the X-ray results obtained for the alumina nanopowders.

The SSA for samples (1)-(3) is in the range of $40-94 \mathrm{~m}^{2} / \mathrm{g}$. Their main component is the $\gamma$-phase of an alumina boehmite line (Figure 1(a)). Sample (4), produced by high-temperature flame hydrolysis, has a higher specific surface area and, again, its main component is the $\gamma$-phase, as is usually mentioned by the manufacturer [9]. Sample (5), produced by the plasmachemical method, has the lowest surface area of $5 \mathrm{~m}^{2} / \mathrm{g}$ and consists of approximately equal quantities of $\delta$ and $\theta$ phases (Figure 1(b)). Note that such an SSA value is not typical for either $\delta$ or $\theta$ alumina, which usually have specific surface areas of about $100 \mathrm{~m}^{2} / \mathrm{g}$. Sample (6), produced by aluminum alkoxide hydrolysis, has a surface area of only $8 \mathrm{~m}^{2} / \mathrm{g}$ and consists of an $\alpha$-alumina phase as shown in Figure 1(c). The X-ray analysis data reveals that the alumina samples all have different phases. It is interesting that the real states of alumina samples (1)-(5), which are produced through gasphase methods, are not strictly the $\gamma$-, $\delta$-, and $\theta$-phases, but they are all in an X-ray amorphous state. Details of X-ray studies of corresponding "semi-amorphous" states can be found in [14].

Figure 2 shows TEM images of the alumina, which clearly illustrate the differences in the shapes and sizes of the nanoparticles. The alumina particles of sample (1) have an almost ideal spherical shape (Figure 2(a)); the same is 


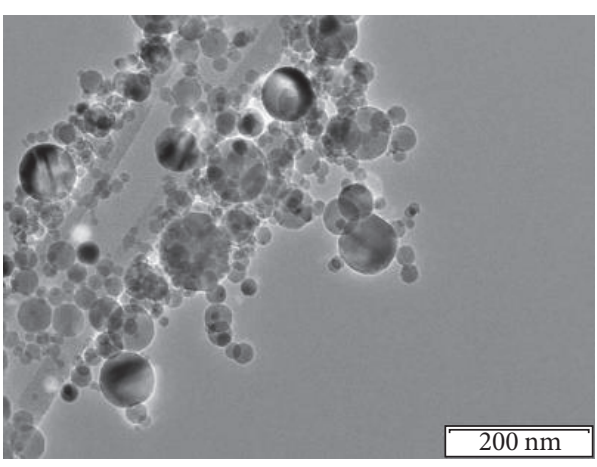

(a)

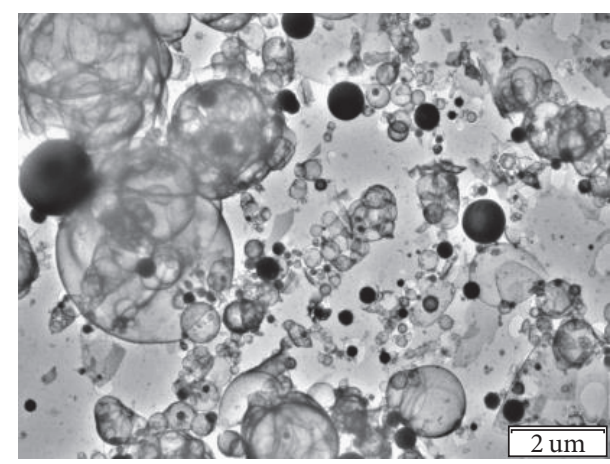

(c)

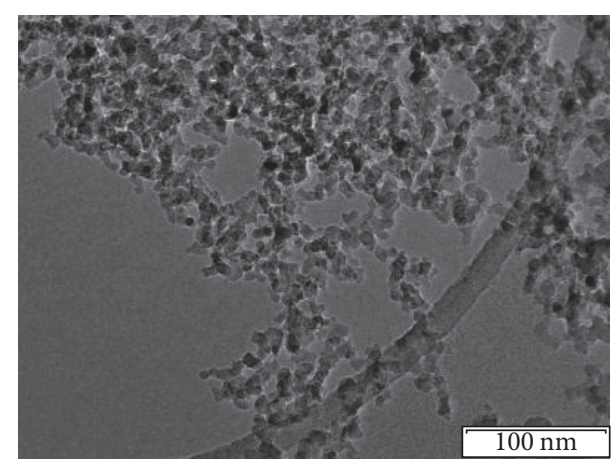

(b)

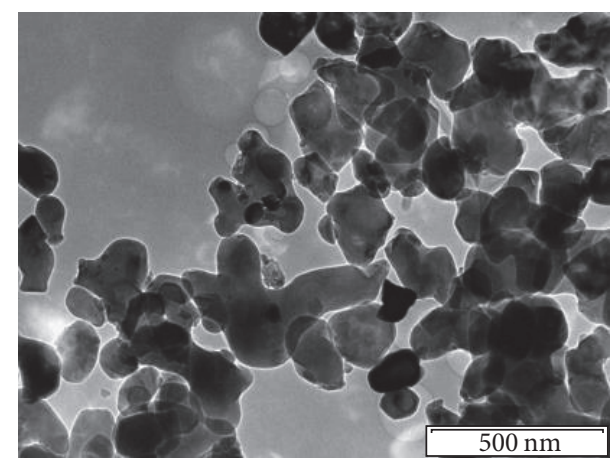

(d)

Figure 2: TEM images of alumina nanoparticles: (a) sample (1), (b) sample (4), (c) sample (5), and (d) sample (6).

true for samples (2) and (3). The APS calculated from the SSA gives values of 40 (Figure $2(\mathrm{a})$ ), 30 , and $18 \mathrm{~nm}$. The particles of sample (4) are not spherical but rather regular with rounded edges, so their APS of about $13 \mathrm{~nm}$ (calculated from SSA, Figure 2(b)) is a typical value [9]. The particles of sample (5) are spherical but mostly hollow and exhibit a wide size distribution. Those of sample (6) are not spherical but irregular although they approximate to a rhomboid shape, which is typical for $\alpha$-alumina. The PSD cannot be obtained for samples (5) and (6) because the analysis software (JEM$100 \mathrm{CX})$ gives very uncertain results for complex-shaped nanoparticles. Nevertheless, the PSD for samples (1) and (4) is narrow (Figures 3(a) and 3(b), calculated from the TEM results) while it is wide for sample (5). For sample (6), most of the particles fall into the range of 100-300 $\mathrm{nm}$.

The specific surface area of the titanium dioxide powders ranges from 42 to $50 \mathrm{~m}^{2} / \mathrm{g}$. Figure 4 presents the X-ray results for titanium dioxide. It is represented by two phases. Samples (7) and (8) are mixtures of similar amounts of anatase and rutile, while sample (9) contains only rutile (see Table 1).

Figure 2 shows that the particles of sample (7) have a structure that is similar to that of sample (1), that is, a spherical shape with an APS of $40 \mathrm{~nm}$ and a PSD similar to that of samples (1)-(3). The particles of sample (8) are irregular in shape, with a particle size of about $30-35 \mathrm{~nm}$ but a sufficiently narrow size distribution. The particles of sample (9) are composed of comparatively large aggregates of acicular nanoparticles with a needle thickness of about $10 \mathrm{~nm}$ and a length of about 30-50 $\mathrm{nm}$.

3.2. Raman Spectroscopy. The Raman spectra (Figure 6) of samples (7) and (8) contain five narrow bands at $144\left(E_{g}\right)$, $197\left(E_{g}\right), 398\left(B_{1 g}\right), 516\left(A_{1 g}\right.$ and $\left.B_{1 g}\right)$, and $639\left(E_{g}\right) \mathrm{cm}^{-1}$. Their frequencies coincide with the frequencies observed in the Raman spectrum of $\mathrm{a} \mathrm{TiO}_{2}$ monocrystalline anatase modification $[15,16]$. The accordance of the bands is shown in parentheses. Sample (7), unlike sample (8), exhibits a sufficiently strong luminescence under laser radiation with an energy level of $1.165 \mathrm{eV}$. The sample (9) spectrum exhibits bands at 120,240,444, and $607 \mathrm{~cm}^{-1}$. All these bands are observed in the spectrum of the $\mathrm{TiO}_{2}$ rutile structure $[15,16]$.

The bands at 120,444, and $607 \mathrm{~cm}^{-1}$ correspond, respectively, to the $B_{1 g}, E_{g}$, and $A_{1 g}$ vibrational modes of rutile. The appearance of a band at $240 \mathrm{~cm}^{-1}$ in the rutile spectrum is associated with the multiphonon Raman process. A noticeable broadening and shift of the bands in the spectrum of sample (9), compared to the spectrum of monocrystalline rutile $\mathrm{TiO}_{2}$, is apparently due to the disordering of the rutile structure in this sample.

The results of Raman spectroscopy were in complete agreement with the data of the phase analysis performed by X-ray diffraction. Additionally, it was found that sample (7) is characterized by an abnormally high luminescence, considering the measurement when excited at $1064 \mathrm{~nm}$. It can 


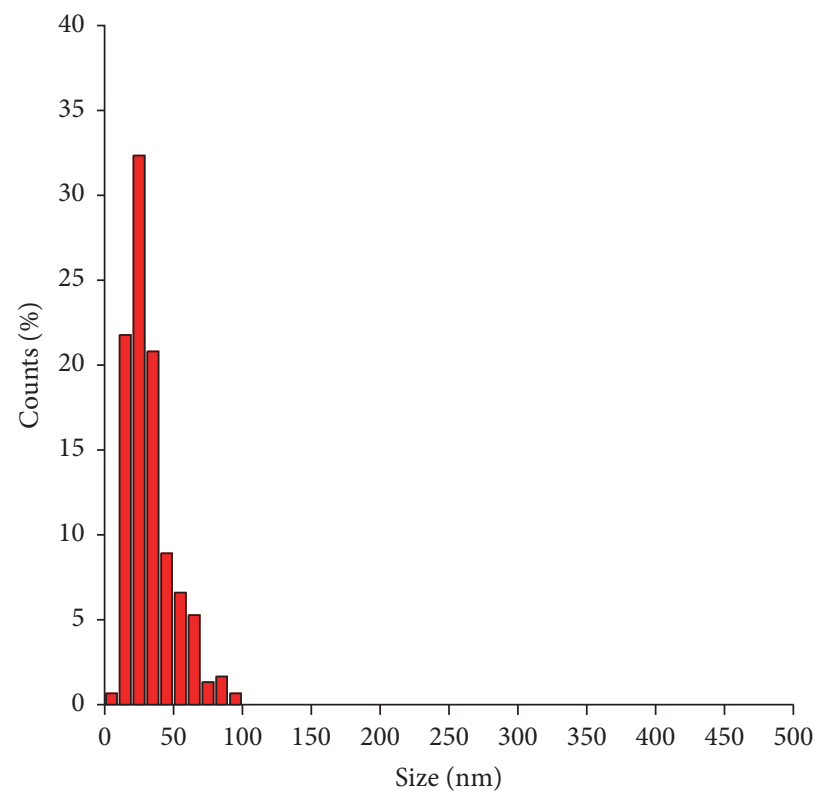

(a)

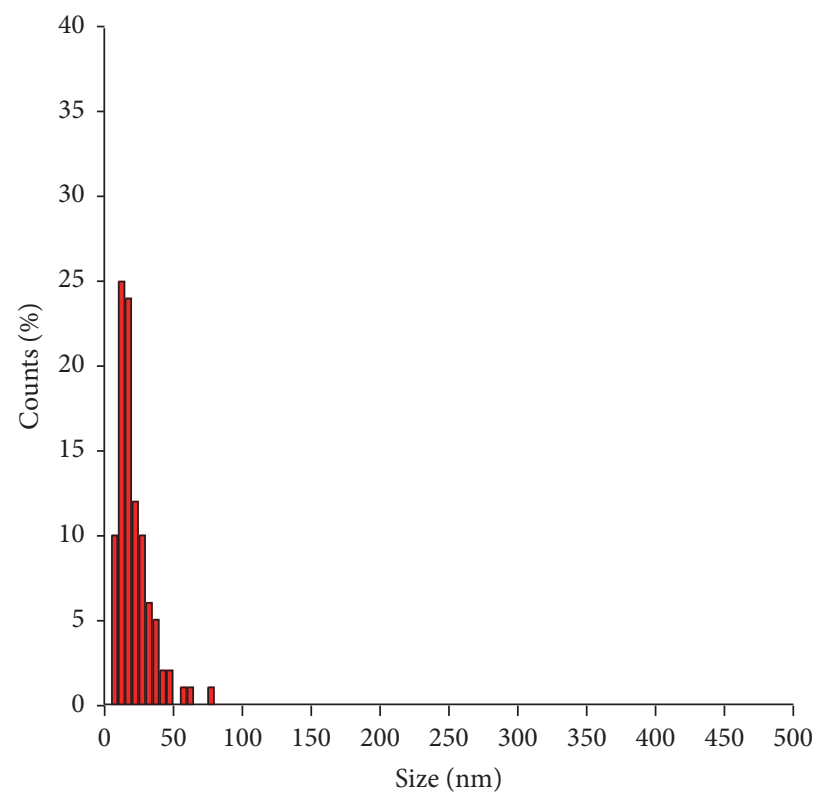

(b)

FIGURE 3: Particle size distribution (PSD) for alumina nanoparticles: (a) sample (1) and (b) sample (4).

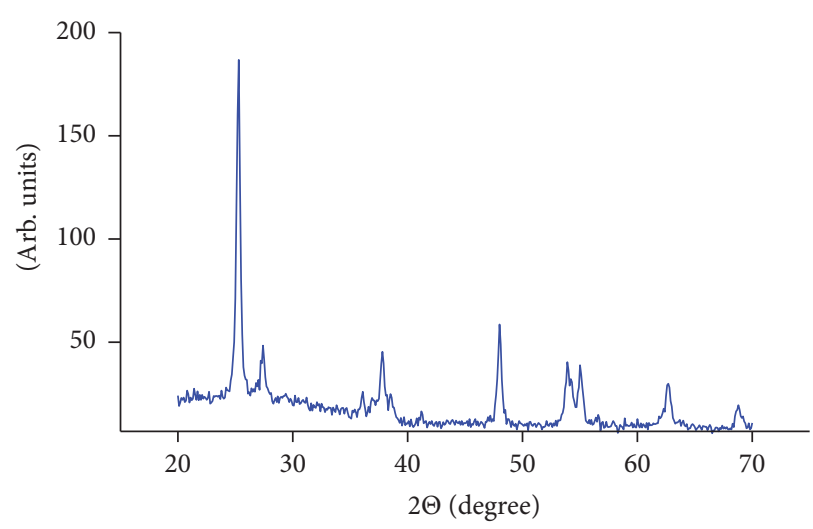

(a)

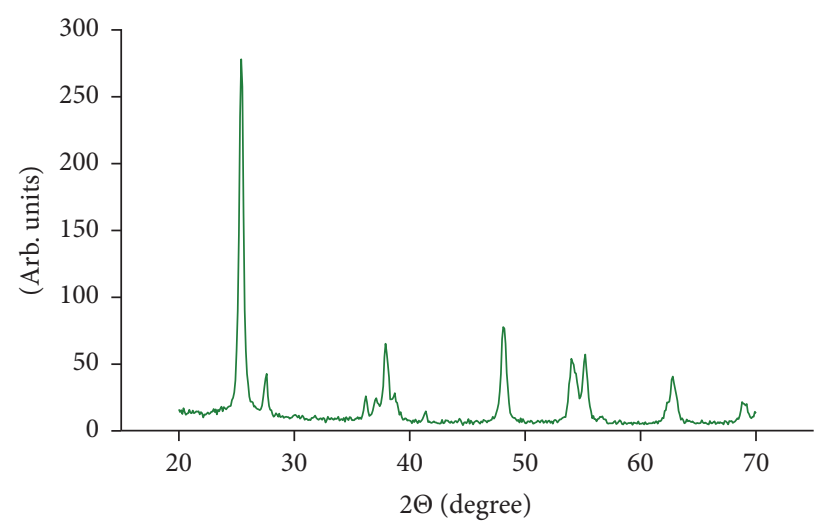

(b)

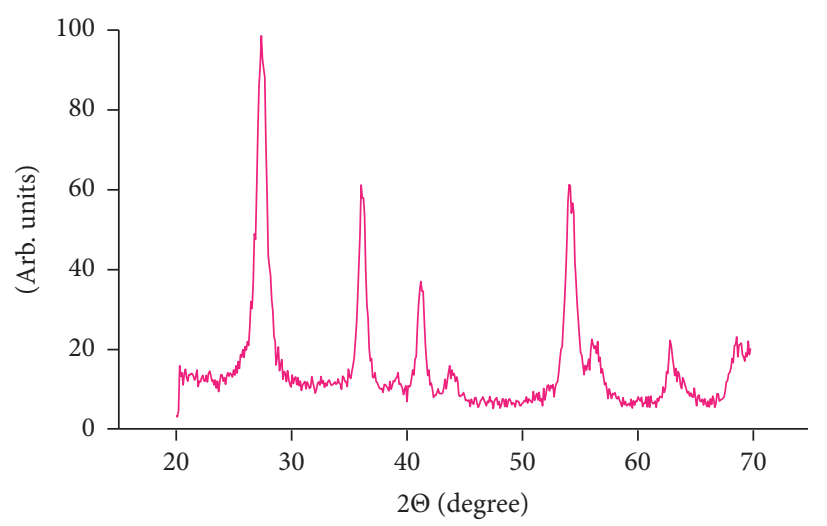

(c)

FIgURE 4: X-ray data for titanium dioxide nanoparticles: (a) sample (7), (b) sample (8), and (c) sample (9). 
be concluded that the anatase in this sample has a high defect density.

3.3. Optical Properties. The UV-Vis-DRS spectra were recorded to study the optical properties of the titanium dioxide samples (Figure 7). The results of the analysis indicate that the visible region has a weak absorption with a maximum at $12,700 \mathrm{~cm}^{-1}$, which is likely to correspond to $\mathrm{Ti}^{3+}$ cations with a coordination number of less than 6 [17]. In the UV region, all the samples have an absorption of more than $25,000 \mathrm{~cm}^{-1}$ with various intensities, depending on the method of nanoparticle synthesis. For sample (9) (Figure 7), two absorption bands can be clearly identified with peaks at 30,000 and $35,500 \mathrm{~cm}^{-1}$.

According to $[17,18]$, these bands can be attributed to oxygen defects $\left(\mathrm{O}_{2}{ }^{-}\right)$, which may appear in the $\mathrm{TiO}_{2}$ structure, depending on the method of sample synthesis. The analysis of the intensity of the absorption bands at 30,000, 35,500 , and $12,700 \mathrm{~cm}^{-1}$ in the UV-Vis-DRS of all the samples showed that as the number of $\mathrm{Ti}^{3+}$ cations with coordination numbers less than 6 increased, the number of oxygen defects $\left(\mathrm{O}_{2}^{-}\right)$in the titanium dioxide structure decreased. This points to the $\mathrm{Ti}^{3+}$ cations with a coordination number of 6 most likely being stabilized on the surface or in the surface layer of the $\mathrm{TiO}_{2}$ structure, while the oxygen defects $\left(\mathrm{O}_{2}{ }^{-}\right)$exist within the $\mathrm{TiO}_{2}$ bulk.

It is well known that $\mathrm{TiO}_{2}$ is an indirect-gap semiconductor [18]. It is characterized by a fundamental absorption edge (or band gap, $E_{g}$ ). Figure 8 shows the absorption spectra of titanium dioxide samples with the function $(\alpha h v)^{1 / 2}=f(h v)$, which determines the photon-energy values corresponding to the $E_{g}$ value. Samples (7) and (8), based of $E_{g}$ values, are two-phase and consist of anatase and rutile modifications, but with different ratios. This is completely consistent with the Xray diffraction (XRD) and Raman data. These $E_{g}$ values are such that we can conclude that sample (9) has an intermediate value between the rutile $E_{g}(3.0 \mathrm{eV})$ and anatase $E_{g}(3.2 \mathrm{eV})$. However, the XRD and Raman methods clearly indicate that this sample has a rutile structure. This means that the band gap width for this sample is not a valid response, since sample (8) is significantly deficient in oxygen.

Thus, the UV-Vis-DRS data allows us to conclude that all the samples are defective to a certain degree and may exhibit different properties, depending on the nature of the defects, that is, whether they are cationic $\left(\mathrm{Ti}^{3+}\right)$ or anionic $\left(\mathrm{O}_{2}{ }^{-}\right)$, with their amount and localization being highly dependent on the sample synthesis method.

\subsection{Surface Properties of Nanoparticles}

3.4.1. Hydroxyl Cover. Figure 9(a) shows the FTIR spectra of the $-\mathrm{OH}$ groups in the alumina samples. For samples (1), (3), (4), and (6), the hydroxyl cover is close to that of conventional alumina. After evacuation at $500^{\circ} \mathrm{C}$, each sample cleared the terminal (above $3750 \mathrm{~cm}^{-1}$ ) and the bridging (3650-3745 $\left.\mathrm{cm}^{-1}\right)-\mathrm{OH}$ groups [13]. Also, hydrogen-bonded $-\mathrm{OH}$ groups, represented by broad unresolved bands below $3600 \mathrm{~cm}^{-1}$, were detected. For $\alpha$-alumina, we observed the same $-\mathrm{OH}$ groups, but the proportion of the terminal $-\mathrm{OH}$ groups is significantly lower. Samples (2) and (5) are characterized by an almost complete lack of terminal and bridging -OH groups and a very high proportion of hydrogen-bonded $-\mathrm{OH}$ groups.

Figure 9(b) shows the FTIR spectra of the hydroxyl groups in the titanium dioxide samples. Samples (7) and (8) show the $-\mathrm{OH}$ groups that are typical for anatase relating to the terminal and bridged $\mathrm{Ti}-\mathrm{OH}$ groups, that is, absorption bands 3743 and $3670 \mathrm{~cm}^{-1}$, respectively. Sample (9) has wide bands of hydrogen-bonded -OH groups. This is likely due to the lamellar crystallites of large rutile agglomerates in the sample (Figure 5). These crystallites are interconnected by hydrogen bonds, which shift the band of the $-\mathrm{OH}$ groups on the surface to below $3600 \mathrm{~cm}^{-1}$ and causes them to broaden.

3.4.2. Lewis Acid Sites. The FTIR spectra of adsorbed pyridine are shown in Figure 10. The bands in the region below $1440 \mathrm{~cm}^{-1}$ and those between 1570 and $1580 \mathrm{~cm}^{-1}$ are attributed to the vibration of the pyridine rings $(\nu \mathrm{CCN} 19 \mathrm{~b}$ and $\nu \mathrm{CCN} 8 \mathrm{~b}$, respectively [19]) of the physically adsorbed pyridine, which was not removed by evacuation at $150^{\circ} \mathrm{C}$. The band at $1485-1495 \mathrm{~cm}^{-1}(\nu \mathrm{CCN} 19 \mathrm{a})$ relates to the vibration of the rings of the physically adsorbed pyridine, which is related to the Lewis acid sites.

Table 2 presents data on the concentration of the Lewis acid sites because Brønsted centers capable of protonating pyridine (region between 1530 and $1550 \mathrm{~cm}^{-1}$ ( $\left.\nu \mathrm{CCN} 19 \mathrm{~b}\right)$ ) have not been found.

Table 2 presents the concentrations of the Lewis centers in micromoles $/ \mathrm{m}^{2}$ and their strengths, characterized by the absorption-band frequency in the ranges 1440-1460 and $1590-1630 \mathrm{~cm}^{-1}$. A previous study [5] showed that the strength of the Lewis centers, determined by the pyridine adsorption heat on the centers, can be estimated by the shift of the $1440-1460$ and $1590-1630 \mathrm{~cm}^{-1}$ bands into the highfrequency region. An increase in the frequency causes the Lewis centers to become stronger. Note, however, that the strength of the Lewis centers on the surface of the titanium dioxide and alumina samples cannot be compared by the frequency shift. This is caused by the relationship between the frequency shift and heat of pyridine adsorption being different for the $\mathrm{Zr}$ and $\mathrm{Al}$ cations [5].

Note that, in certain cases, the nanoparticles displayed centers that could be comparable in terms of strength to alumina in the solid state.

The table shows that samples (1)-(4) and (6), (7) are sufficiently homogeneous and that only a single type of center can be detected. Samples (5), (8), and (9) show the centers of two types (spectra obtained after evacuation at $400^{\circ} \mathrm{C}$ ). An increase in the concentration of the stronger centers is obviously accompanied by a drop in the proportion of the weaker centers.

For alumina, sample (2) has the weakest acid sites, whereas those for sample (4) are the strongest. Sample (5) has acid sites with next level of strength. For titanium dioxide, sample (7) exhibits the largest concentration of acid sites at a frequency of $1453 \mathrm{~cm}^{-1}$. The strength of the Lewis 


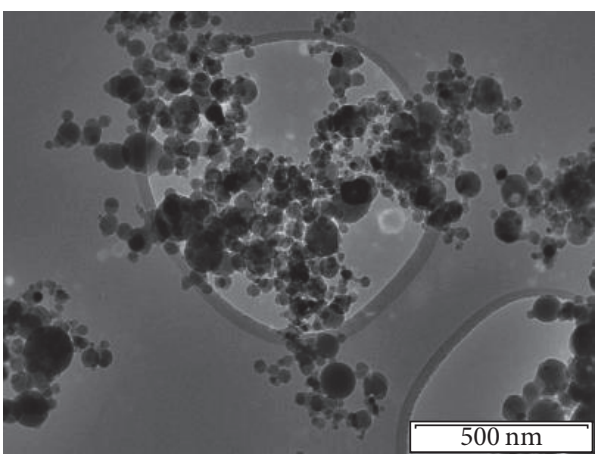

(a)

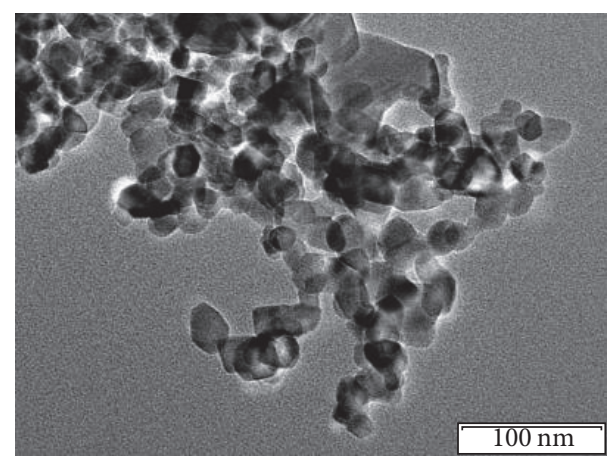

(b)

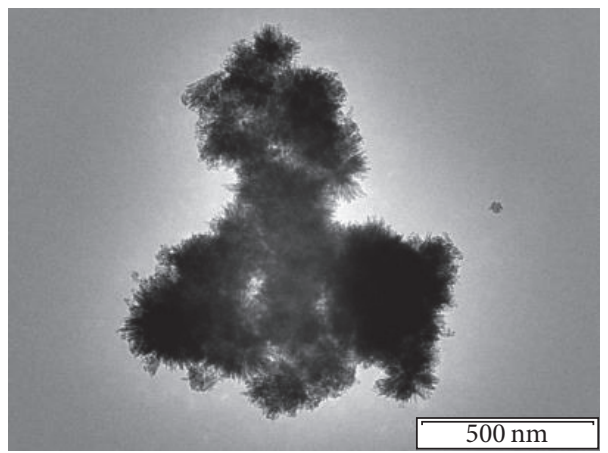

(c)

FIGURE 5: TEM images of titanium dioxide nanoparticles: (a) sample (7), (b) sample (8), and (c) sample (9).

TABle 2: Properties of Lewis centers of samples.

\begin{tabular}{|c|c|c|c|c|c|}
\hline Number & $\begin{array}{l}\text { Sample } \\
\text { number }\end{array}$ & $\begin{array}{c}\text { Frequency in } \\
1440-1460 \mathrm{~cm}^{-1} \text { range }\end{array}$ & $\begin{array}{c}\text { Frequency in } \\
1590-1630 \mathrm{~cm}^{-1} \text { range }\end{array}$ & $\begin{array}{l}\text { Concentration, } \\
\text { micromole } / \mathrm{m}^{2}\end{array}$ & Synthesis method \\
\hline \multicolumn{6}{|c|}{ Alumina } \\
\hline (1) & $(1)$ & 1447 & 1604 & 0.68 & (A) Electron beam evaporation [8] \\
\hline$(2)$ & (2) & 1445 & 1594 & 0.92 & (A) Electron beam evaporation [8] \\
\hline (3) & (3) & 1450 & 1613 & 0.45 & (A) Electron beam evaporation [8] \\
\hline (4) & (4) & 1454 & 1622 & 0.52 & (C) High-temperature flame hydrolysis [9] \\
\hline \multirow{2}{*}{ (5) } & \multirow{2}{*}{ (5) } & 1449 & 1612 & 11.90 & \multirow{2}{*}{ (D) Plasma-chemistry method [10] } \\
\hline & & 1455 & 1615 & 3.20 & \\
\hline$(6)$ & $(6)$ & 1448 & 1610 & 2.70 & (B) Hydrolysis of aluminum alkoxide [11] \\
\hline \multicolumn{6}{|c|}{ Titanium dioxide } \\
\hline (7) & (7) & 1453 & 1608 & 0.78 & (A) Electron beam evaporation [8] \\
\hline \multirow{2}{*}{ (8) } & \multirow{2}{*}{$(8)$} & 1445 & 1602 & 3.10 & \multirow{2}{*}{ (C) High-temperature flame hydrolysis [9] } \\
\hline & & 1453 & 1610 & 0.12 & \\
\hline \multirow{2}{*}{ (9) } & \multirow{2}{*}{ (9) } & 1443 & 1604 & 2.70 & \multirow{2}{*}{ (E) Sulfate process [12] } \\
\hline & & 1453 & 1610 & 0.32 & \\
\hline
\end{tabular}

centers is the same for all the titanium dioxide samples. The concentration of the acid sites for sample (7) was only a quarter of that of the samples produced by other synthesis methods.

\section{Discussion}

Analysis performed by several conventional methods showed that the material properties depend on the method by which the nanoparticles were synthesized. If we consider a common set of material properties that are determined by their phase, it appears that, for some methods of synthesis, the nanoparticles have special features. Of note are the special luminescence characteristic of $\mathrm{TiO}_{2}$ (sample (7)), a photonenergy shift from the rutile region in the region typical for the anatase (sample (9)), and a significant difference in the intensity of the Lewis centers for the alumina $\gamma$ phase (samples (1)-(4)). This variation in the properties of the 


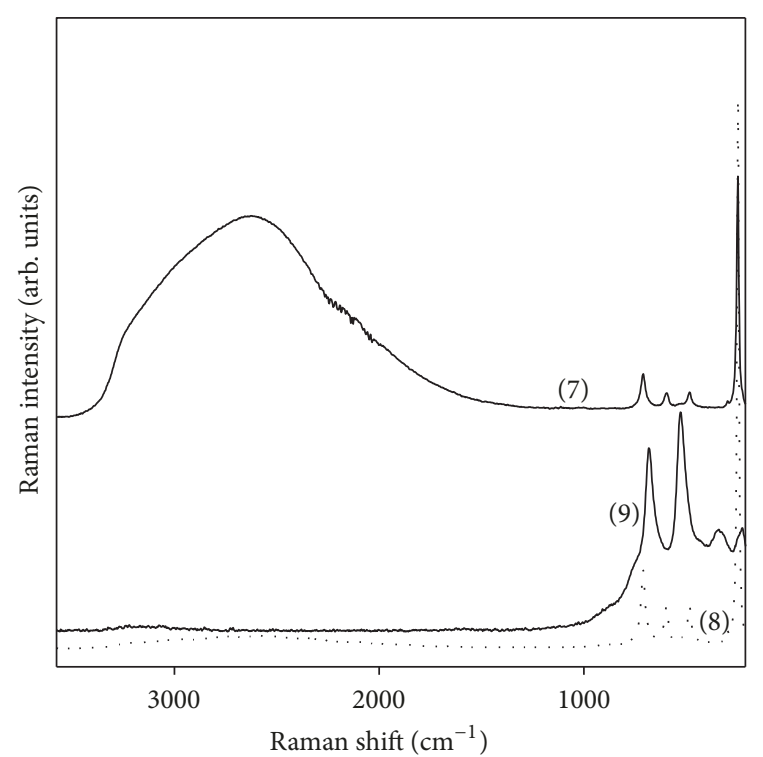

FIGURE 6: Raman spectra of titanium dioxide samples (7), (8), and (9).

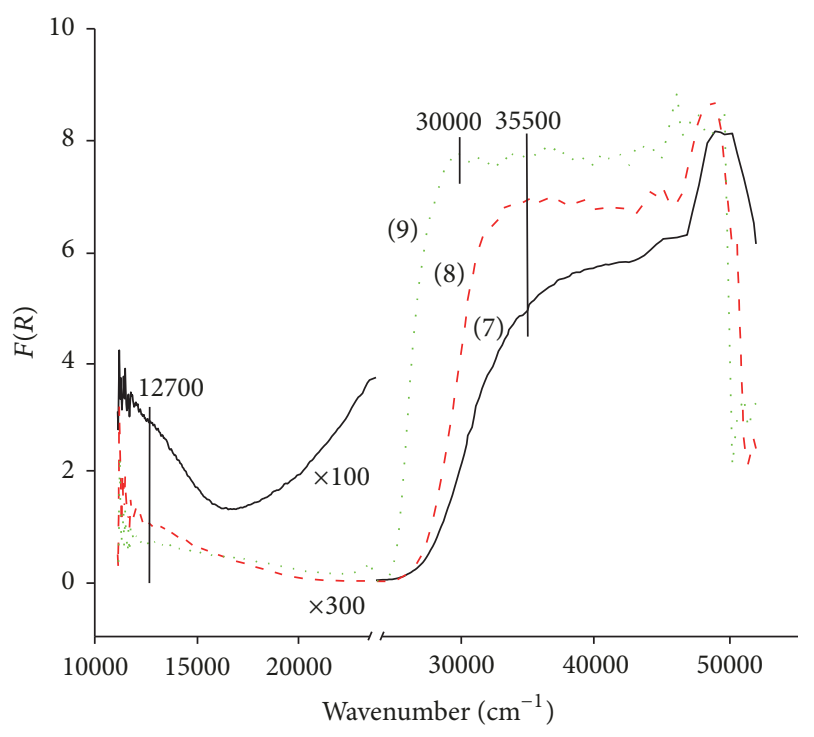

FIGURE 7: UV-Vis-DR spectra of titanium dioxide samples (7), (8), and (9).

samples points to the need to involve a wider range of material analysis techniques and the importance of precisely characterizing the surface properties.

As was mentioned previously, the synthesis conditions determine the nature of the atomic interactions, the process, and the conditions of their association while organizing the nanoparticles. These differences can arise in every stage of cluster formation [3]. When the cluster concentration is sufficiently high, it is possible to rebuild them, leading to a change in the surface structure. In a previous study

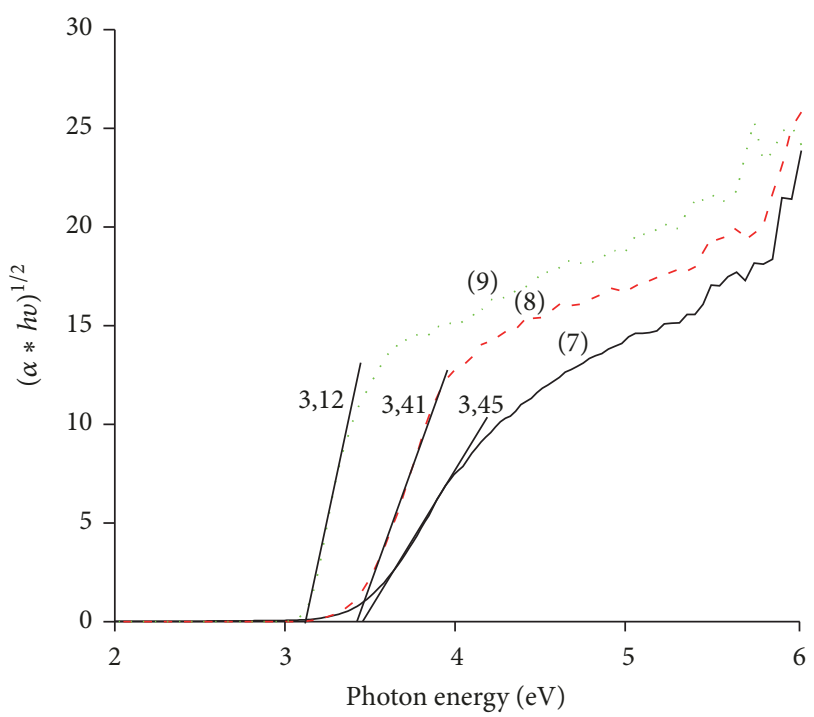

Figure 8: Dependencies of $(\alpha h \nu)^{1 / 2}=f(h \nu)$ for $\mathrm{TiO}_{2}$ samples (7), (8), and (9).

[2], it was shown that the silica nanoparticles can exhibit a different surface distribution of silicon and oxygen atoms, which is explained by the Lewis center distribution. The samples investigated in [2] were synthesized using the same methods as those used to produce samples (1) and (4), and (7) and (8), indicating the same possibility for alumina and titanium dioxide nanoparticles.

In practice, such a variation in the surface properties results in a change in the interaction between the nanoparticles and their environment (polymers, metals, and so on). For example, it is possible to change the viscosity of a fluid by using nanoparticles which are chemically identical but which have been produced using different methods [20].

\section{Conclusion}

A comparative study of the volume and surface properties of nanoparticles was carried out by FTIR, UV-Vis DR, and Raman spectroscopy, as well as X-ray diffraction methods. It was shown that variations in the synthesis method can produce changes in the surface properties of the nanoparticles, while maintaining the phase composition of the material. The nanoparticles exhibit unique properties not normally associated with their phase. To identify the functional properties of the nanoparticles, which determine their interaction with other materials, comprehensive studies of the phase consistency and surface properties must be carried out.

\section{Conflicts of Interest}

The authors declare no conflicts of interest regarding the publication of this paper. 


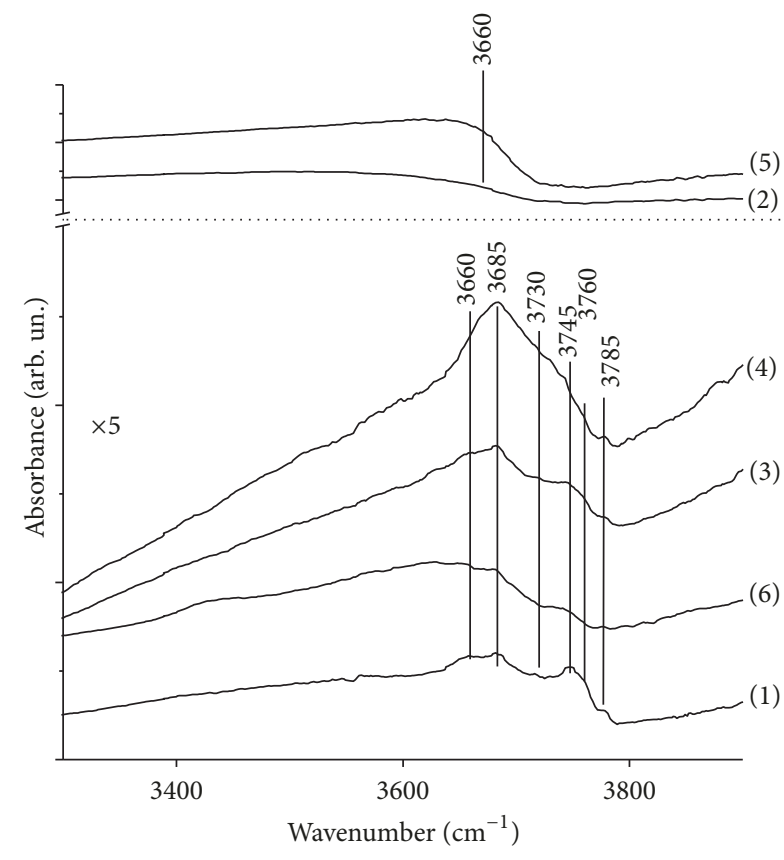

(a)

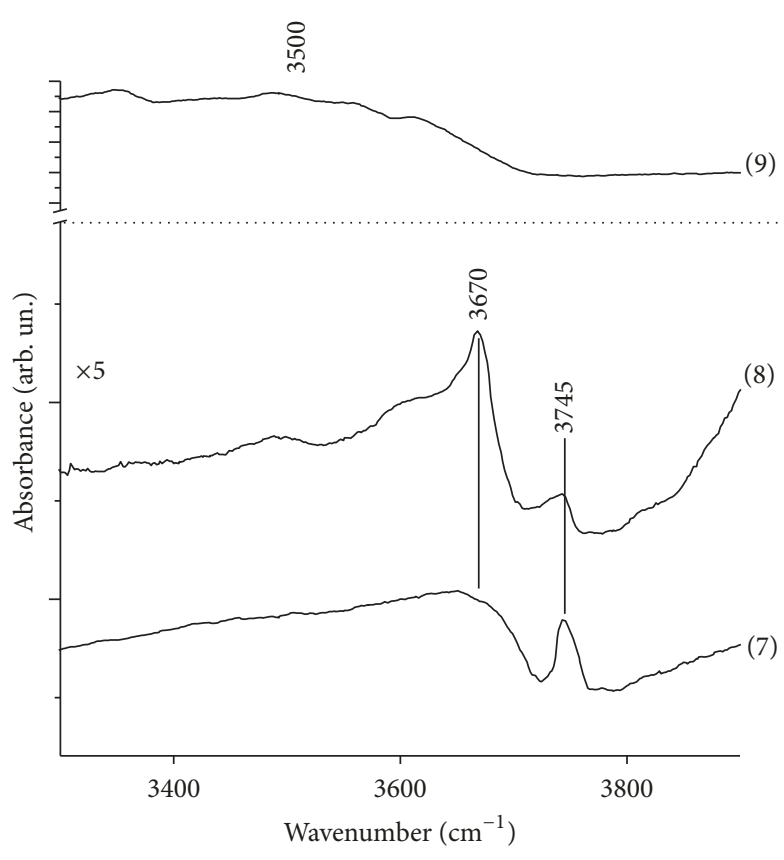

(b)

FIgURE 9: FTIR spectra of hydroxyl groups in (a) alumina and (b) titanium dioxide samples.

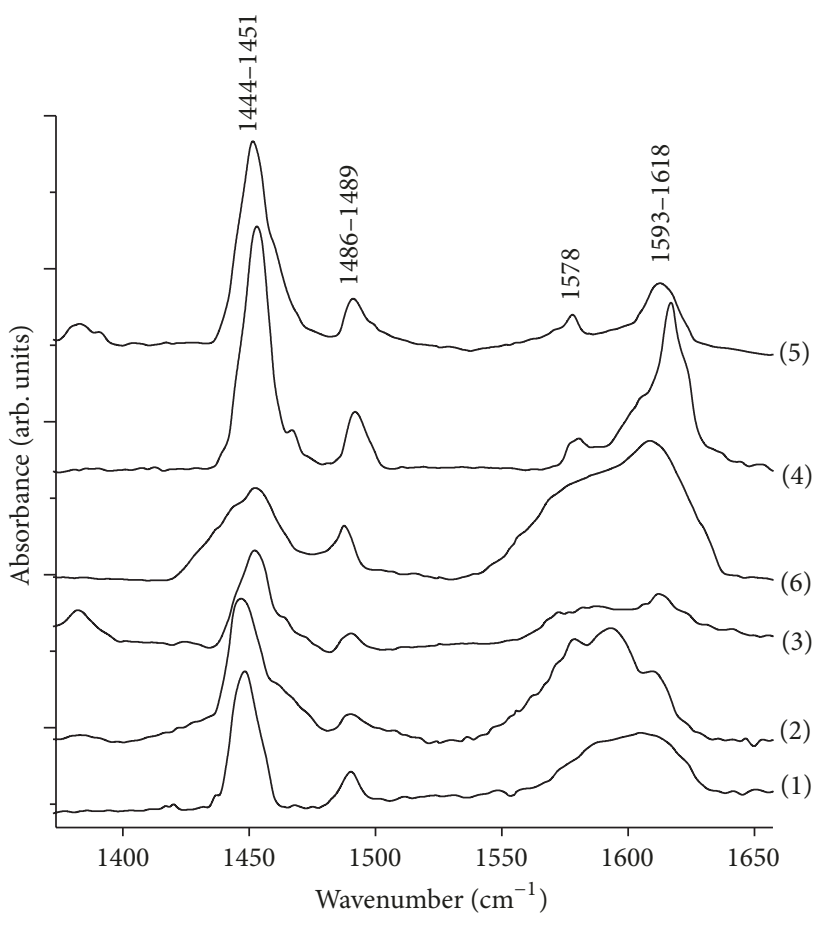

(a)

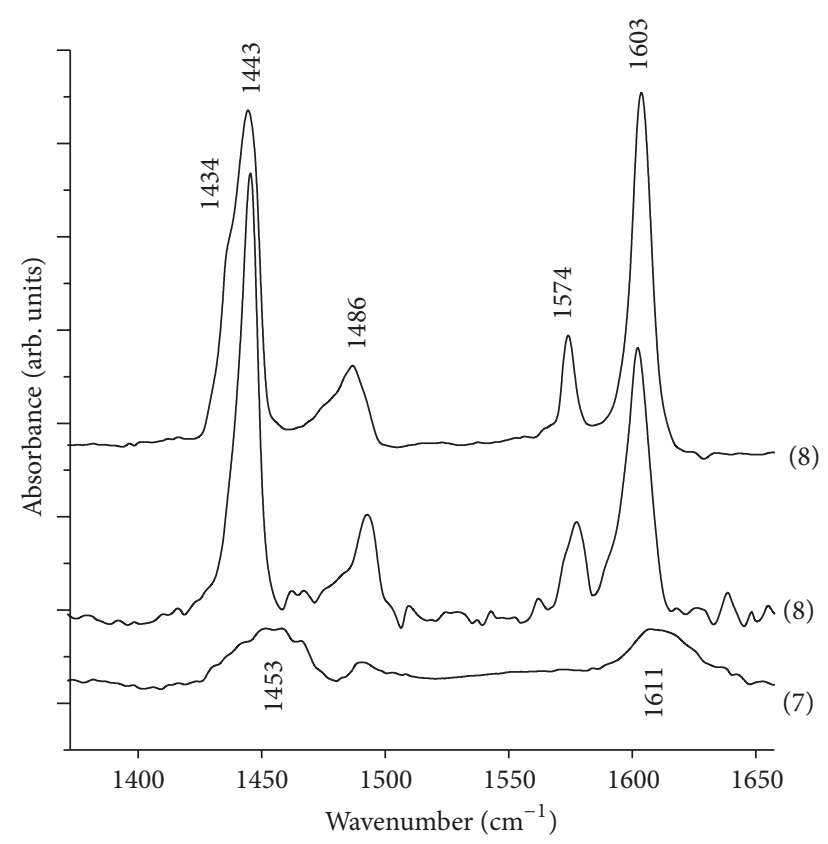

(b)

FIGURE 10: FTIR spectra of adsorbed pyridine in (a) alumina and (b) titanium dioxide samples.

\section{Acknowledgments}

This work was financially supported by a 2017 grant of the Russian Science Foundation, Project no. 17-19-01389.

\section{References}

[1] E. F. Sheka, V. D. Khavryuchenko, and I. V. Markichev, "Techonological polymorphism of disperse amorphous silicas: 
inelastic neutron scattering and computer modelling," Russian Chemical Reviews, vol. 64, no. 5, pp. 389-414, 1995.

[2] S. P. Bardakhanov, I. V. Vasiljeva, N. K. Kuksanov, and S. V. Mjakin, "Surface functionality features of nanosized silica obtained by electron beam evaporation at ambient pressure," Advances in Materials Science and Engineering, vol. 2010, Article ID 241695, 5 pages, 2010.

[3] M. Y. Gen and Y. I. Petrov, "Disperse condensates of metal vapour," Russian Chemical Reviews, vol. 38, no. 12, pp. 10071024, 1969.

[4] V. D. Khavryuchenko and E. F. Sheka, "Computational modeling of amorphous silica. 2. Modeling the initial structures. Aerosil," Journal of Structural Chemistry, vol. 35, no. 3, pp. 291298, 1994.

[5] E. A. Paukshtis and E. N. Yurchenko, "Study of the acid-base properties of heterogeneous catalysts by infrared spectroscopy," Russian Chemical Reviews, vol. 52, no. 3, pp. 242-258, 1983.

[6] A. A. Lamberov, R. G. Romanova, I. G. Shmelev, and V. F. Sopin, "Effect of acid modification on the structure and catalytic activity of aluminum oxide," Russian Journal of Applied Chemistry, vol. 75, no. 3, pp. 396-401, 2002.

[7] C. Morterra, V. Bolis, and G. Magnacca, "IR spectroscopic and microcalorimetric characterization of Lewis acid sites on (transition phase) Al2O3 using adsorbed CO," Langmuir, vol. 10, no. 6, pp. 1812-1824, 1994.

[8] S. P. Bardakhanov, A. I. Korchagin, N. K. Kuksanov et al., "Nanopowder production based on technology of solid raw substances evaporation by electron beam accelerator," Materials Science and Engineering: B, vol. 132, no. 1-2, pp. 204-208, 2006.

[9] M. Ettlinger, "Hochdisperse metalloxide nach dem Aerosilverfaren," Schriftenreihe Pigmente, vol. 56, pp. 1-39, 1989 (German).

[10] V. K. Larin, V. M. Kondakov, E. N. Maly et al., "Plasma-chemical method for obtaining ultradisperse (nano-) powders of metal oxides and promising directions of their application, Izvestiya Vysshikh Uchebnykh Zavedenii," Tsvetnaya Metallurgiya Russian Journal of Non-Ferrous Metals, vol. 5, pp. 59-64, 2003.

[11] S. Fujiwara, Y. Tamura, H. Maki, N. Azuma, and Y. Takeuchi, "Development of new high-purity alumina," Sumitomo Kagaku, pp. 1-10, 2007.

[12] Nano Chemical Inc, http://www.nanoxides.com/.

[13] T. R. Hughes and H. M. White, "A study of the surface structure of decationized Y zeolites by quantitative infrared spectroscopy," Journal of Physical Chemistry A, vol. 71, pp. 21922202, 1967.

[14] U. A. Abzaev, V. V. Syzrantsev, and S. P. Bardakhanov, "Modeling of the structural state of amorphous phases of the nanosized $\mathrm{Al} 2 \mathrm{O} 3$ produced by different synthesis methods," Russian Physics Journal, vol. 60, no. 3, pp. 129-135, 2017.

[15] T. Ohsaka, F. Izumi, and Y. Fujiki, "Raman spectrum of anatase, $\mathrm{TiO}_{2}$," Journal of Raman Spectroscopy, vol. 7, no. 6, pp. 321-324, 1978.

[16] L. D. Arsov, C. Kormann, and W. Plieth, "Electrochemical synthesis and in situ Raman spectroscopy of thin films of titanium dioxide," Journal of Raman Spectroscopy, vol. 22, no. 10, pp. 573-575, 1991.

[17] A. B. P. Lever, "Inorganic electronic spectroscopy," Studies in Physical and Theoretical Chemistry, vol. 33, 1986.

[18] J. Strunk, W. C. Vining, and A. T. Bell, "A study of oxygen vacancy formation and annihilation in submonolayer coverages of TiO2 dispersed on MCM-48," The Journal of Physical Chemistry C, vol. 114, no. 40, pp. 16937-16945, 2010.
[19] M. I. Zaki, M. A. Hasan, F. A. Al-Sagheer, and L. Pasupulety, "In situ FTIR spectra of pyridine adsorbed on $\mathrm{SiO}_{2}-\mathrm{Al}_{2} \mathrm{O}_{3}, \mathrm{TiO}_{2}$, $\mathrm{ZrO}_{2}$ and $\mathrm{CeO}_{2}$ : general considerations for the identification of acid sites on surfaces of finely divided metal oxides," Colloids and Surfaces A: Physicochemical and Engineering Aspects, vol. 190, no. 3, pp. 261-274, 2001.

[20] V. V. Syzrantsev, A. P. Zavyalov, and S. P. Bardakhanov, "The role of associated liquid layer at nanoparticles and its influence on nanofluids viscosity," International Journal of Heat and Mass Transfer, vol. 72, pp. 501-506, 2014. 


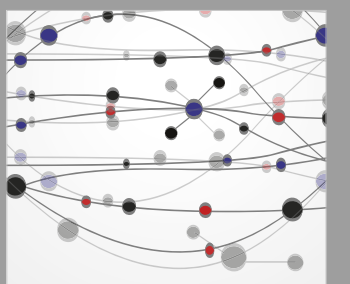

The Scientific World Journal
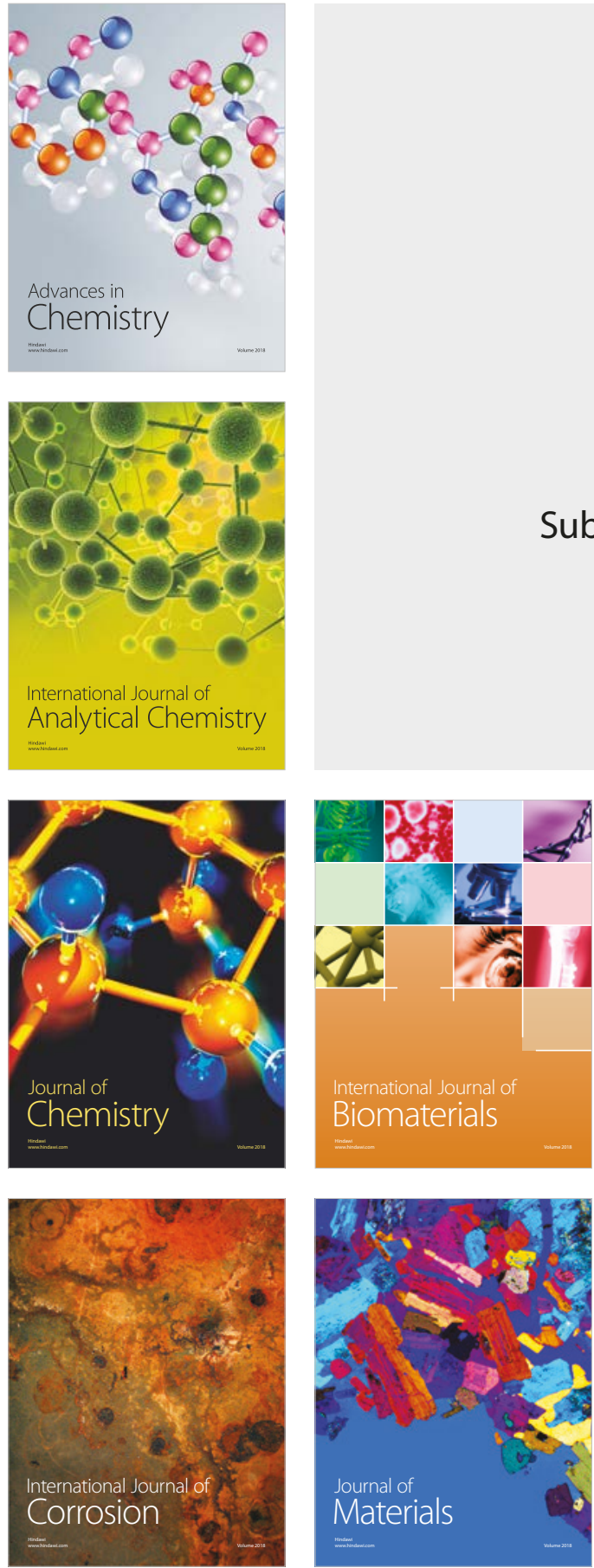

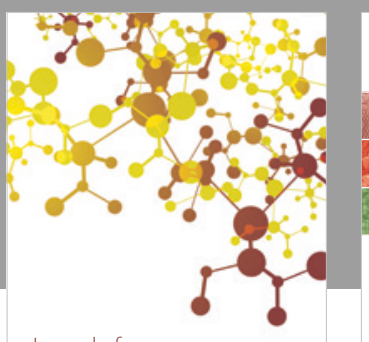

Journal of

Applied Chemistry
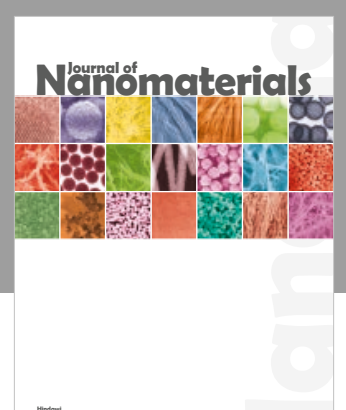

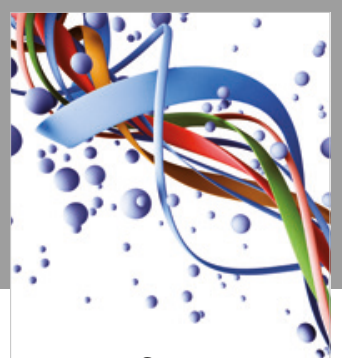

Scientifica

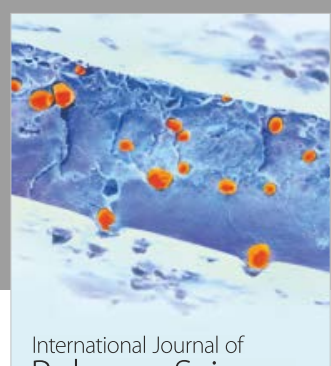

Polymer Science

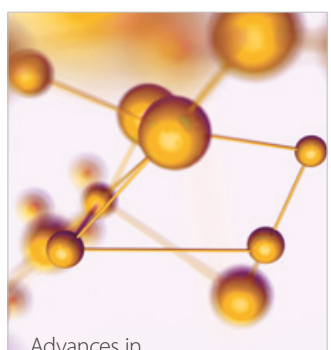

Physical Chemistry
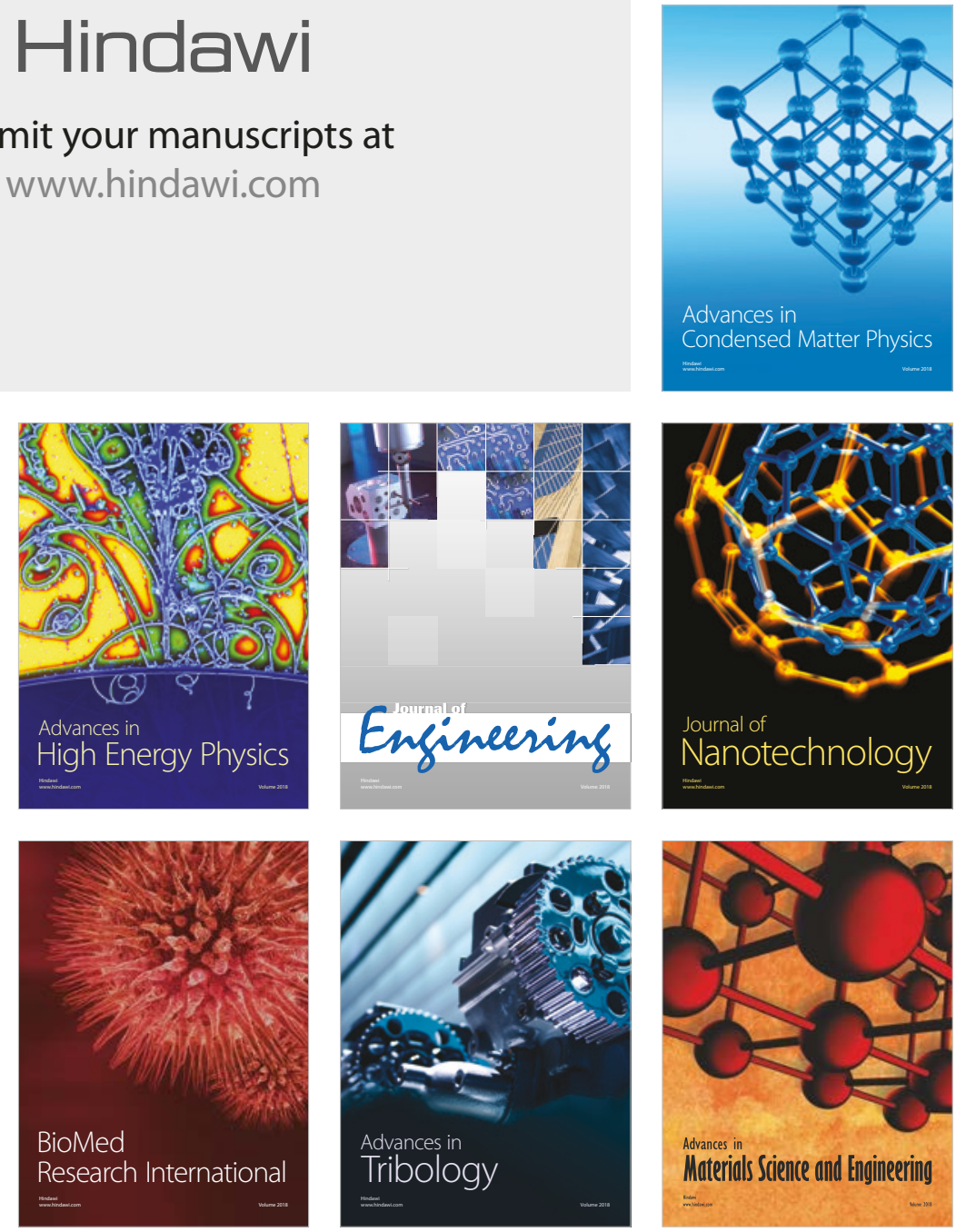